\title{
PERSEPSI MAHASISWA TERHADAP MODEL PROJECT BASED LEARNING DALAM PENYUSUNAN KURIKULUM TINGKAT SATUAN PENDIDIKAN
}

\author{
Chandrawaty $^{1}$, Khusniyati Masykuroh ${ }^{2}$ \\ ${ }^{\mathbf{1 , 2}}$ Universitas Muhammadiyah Prof. DR. HAMKA \\ Email : chandrawaty@uhamka.ac.id, khusniyati.masykuroh@uhamka.ac.id
}

\begin{abstract}
This study aims to determine student perceptions of the project-based learning model in the preparation of the Education Unit Level Curriculum (KTSP). Data collection used questionnaires and documentation, while data analysis techniques used quantitative descriptive analysis. Research location on the campus of the Faculty of Teacher Training and Education, University of Muhammadiyah Prof. DR. HAMKA. The research subjects were all 22 semesters 5 Early Childhood Teacher Education Study Program students who took Curriculum Development courses in 2019/2020 Academic Year. The results of the study showed: 1) $100 \%$ of students said that after arranging KTSP through project-based learning, their mastery of curriculum development subjects was increased; 2) $95 \%$ of students said that through project-based learning increases the depth of curriculum development analysis; 3) 95\% of students said that every teacher must master the skills in preparing KTSP; 4) 95\%of students said that they would apply their KTSP skills when becoming early childhood teachers.
\end{abstract}

Keywords: perception; project-based learning, Education Unit Level Curriculum,

\begin{abstract}
ABSTRAK
Penelitian ini bertujuan untuk mengetahui persepsi mahasiswa terhadap model project based learning dalam penyusunan Kurikulum Tingkat Satuan Pendidikan (KTSP). Pengumpulan data menggunakan angket dan dokumentasi, sedangkan teknik analisa data menggunakan analisis deskriptif kuantitatif. Lokasi penelitian di kampus Fakultas Keguruan dan Ilmu Pendidikan Universitas Muhammadiyah Prof. DR. HAMKA, Jakarta. Penelitian ini menggunakan teknik pengambilan data purposive sampling. Subjek penelitian adalah seluruh mahasiswa program studi Pendidikan Guru Pendidikan Anak Usia Dini semester 5 berjumlah 22 yang mengambil mata kuliah Pengembangan Kurikulum pada Tahun Akademik 2019/2020. Hasil penelitian menunjukkan : 1) 100\% mahasiswa mengatakan setelah menyusun KTSP melalui project based learning meningkatkan penguasaan mata kuliah pengembangan kurikulum; 2) 95\% mahasiswa menyampaikan bahwa melalui project based learning meningkatkan kedalaman analisis pengembangan kurikulum; 3) 95\% mahasiswa menyampaikan bahwa setiap guru harus menguasai keterampilan menyusun KTSP; 4) 95\% mahasiswa menyampaikan bahwa akan mengaplikasikan keterampilan menyusun KTSP saat menjadi guru PAUD.
\end{abstract}

Kata kunci : persepsi; project based learning; Kurikulum Tingkat Satuan Pendidikan

\section{PENDAHULUAN}

Pendidikan berkualitas menjadi tugas bersama semua negara di dunia. Melalui kesepakatan oleh 193 negara pada bulan September 2015 melalui sidang umum PBB, menandatangani program pembangunan berkelanjutan yang dikenal sebagai Sustainable Development Growths (SDGs), berlaku sejak tahun 2015 sampai dengan 2030. 
Program SDGs terdiri dari 17 tujuan, 169 target pembangunan, dan 230 indikator tambahan SDGs merupakan dokumen kesepakatan global untuk melaksanakan pembangunan berkelanjutan menghadapi tantangan pada proses pembangunan (Fardan Ngoyo, 2015). Pemerintah Indonesia menyelaraskan program SDGs dengan Rencana Pembangunan Jangka Menengah Nasional 2015-2019 dalam hal pendidikan berkualitas antara lain pada tahun 2030 menjamin akses yang sama bagi semua perempuan dan lakilaki,terhadap pendidikan teknik, kejuruan, dan pendidikan tinggi, termasuk universitas, yang terjangkau dan berkualitas (ILO, 2018).

Perguruan Tinggi menjalankan peran untuk memberikan pendidikan berkualitas untuk mahasiswa supaya siap menghadapi tantangan abad 21 dengan memiliki keterampilan komunikasi yang baik, berpikir kritis, kreatif, dan bekerjasama. Hal ini sejalan dengan Undang-Undang No. 20, Tahun 2003 tentang Sistem Pendidikan Nasional. Pada pasal 3 disebutkan bahwa Pendidikan nasional berfungsi mengembangkan kemampuan dan membentuk watak serta peradaban bangsa yang bermartabat dalam rangka mencerdaskan kehidupan bangsa, bertujuan untuk berkembangnya potensi peserta didik agar menjadi manusia yang beriman dan bertakwa kepada Tuhan Yang Maha Esa, berakhlak mulia, sehat, berilmu, cakap, kreatif, mandiri, dan menjadi warga negara yang demokratis serta bertanggung jawab (Depdiknas, 2003).
Peraturan Menteri Riset, Teknologi, dan Pendidikan Tinggi No 44 Tahun 2015 tentang Standar Nasional Pendidikan Tinggi menyebutkan bahwa kurikulum di pendidikan tinggi adalah seperangkat rencana dan pengaturan mengenai capaian pembelajaran lulusan, bahan kajian, proses, dan penilaian yang digunakan sebagai pedoman penyelenggaraan program studi (Nurwardani et al., 2016). Mengacu pada Kerangka Kualifikasi Nasional Indonesia (KKNI) (Nurdin, 2017), maka langkah yang harus diambil oleh pengembang kurikulum pendidikan tinggi adalah : 1) Merumuskan profi lulusan yang menggambarkan secara jelas dan spesifik sosok lulusan yang akan dihasilkan oleh suatu program studi; 2) Menetapkan capaian pembelajaran atau kompetensi, yaitu kemampuan yang diperoleh melalui internalisasi pengetahuan, sikap, keterampilan, kompetensi, dan pengalaan kerja; 3) Memilih dan merumuskan bahan kajian yang akan dipelajari. Bahan kajian diambil dari rumpun ilmu yang menjadi ciri program studi atau dari khazanah keilmuan yang akan dibangun oleh program studi; 4) Menetapkan mata kuliah yang akan diajarkan di program studi.

Mata kuliah Pengembangan Kurikulum merupakan salah satu mata kuliah wajb program studi Pendidikan Guru PAUD (PG PAUD) di Fakultas Keguruan dan Ilmu Pendidikan (FKIP), Universitas Muhammadiyah Prof. DR. HAMKA. Mata kuliah ini berfungsi membekali mahasiswa calon guru dengan pemahaman dan wawasan yang 
komprehensif tentang konsep secara teoretik dan hal yang bersifat praktis yang berhubungan dengan konsep dan dimensi, landasan, prinsip, dan perkembangan kurikulum di Indonesia, model, evaluasi, dan inovasi pengembangan kurikulum. Mata kuliah ini diikuti oleh mahasiswa semester 5 program studi PG PAUD dengan beban studi sebesar 3 satuan kredit semester.

Mata kuliah tersebut di atas merupakan mata kuliah wajib yang harus diikuti para mahasiswa calon guru PAUD untuk mendapatkan pemahaman dan wawasan yang komprehensif tentang pengembangan kurikulum. Kurikulum sendiri adalah pengalaman pembelajaran yang terencana dan terarah dengan baik, yang disusun melalui proses rekonstruksi pengetahuan dan pengalaman yang sistematis di bawah pengawasan lembaga pendidikan agar pembelajaran dapat terus terjaga. Melalui mata kuliah ini, mahasiswa dituntut untuk selalu mengikuti perkembangan kemajuan pendidikan, karena kurikulum harus dinamis dan mampu menghadapi tantangan kemajuan zaman.

Mata kuliah ini menuntut mahasiswa untuk aktif dalam memahami dan menganalisis pengembangan kurikulum, serta mampu merancang inovasi kurikulum pembelajaran dengan menyusun Kurikulum Tingkat Satuan Pendidikan. Oleh karena itu dosen perlu memilih model pembelajaran yang mampu mendorong mahasiswa untuk belajar mandiri dengan mengembangkan sikap, pengetahuan, keterampilan. Salah satu model pembelajaran yang bisa menjawab tantangan tersebut di atas adalah project based learning (pembelajaran berbasis proyek). Model pembelajaran project based learning dapat mendukung pembelajaran aktif dan memberikan keterampilan bekerjasama dalam kelompok (Trisnowati, Ismawati, \& Tidar, 2018). Pembelajaran proyek juga melatih berpikir kritis terhadap terhadap permasalahan kontekstual yang berkaitan dengan materi, sehingga dapat meningkatkan kemampuan kognitif mulai dari menganalisis, mensintesis, mengevaluasi, dan mencipta (Insyasiska, Zubaidah, Susilo, Biologi, \& Malang, 2015). Project based learning sangat memperhatikan proses kerja yang sistematis saat menghasilkan karya yang nyata dan bermanfaat (Sutirman, 2013). Melalui project based learning dosen merancang suatu proyek yang sistematik agar mahasiswa belajar pengetahuan dan keterampilan melalui proses pencarian (inquiry) yang terstruktur dan kompleks. Mahasiswa akan mengerjakan proyek tersebut dan menunjukkan kinerja, serta mempertanggungjawabkan kinerjanya di forum (Direktorat Akademik, 2008).

Penelitian ini bertujuan untuk mengetahui persepsi mahasiswa terhadap model project based learning dalam penyusunan Kurikulum Tingkat Satuan Pendidikan (KTSP). Persepsi dapat dirumuskan sebagai suatu proses penerimaan, pemilihan, pengorganisasian, serta pemberian arti terhadap rangsang yang diterima (Nurjaman, Rachmi, \& Arjulayana, 2019) . 
Adapun masalah yang dihadapi dibatasi dalam : 1) Persepsi mahasiswa apakah melalui model project based learning dalam menyusun KTSP meningkatkan penguasaan mata kuliah pengembangan kurikulum; 2) Persepsi mahasiswa apakah melalui model project based learning meningkatkan kedalaman analisis pengembangan kurikulum; 3) Persepsi mahasiswa apakah akan mengaplikasikan keterampilan menyusun KTSP saat menjadi guru PAUD; 4) Persepsi mahasiswa apakah setiap guru penting untuk menguasai keterampilan menyusun KTSP.

\section{METODE PENELITIAN}

Penelitian ini dilakukan untuk memperoleh data persepsi mahasiswa terhadap mata kuliah Pengembnagan Kurikulum. Pendekatan yang digunakan adalah kuantitatif deskriptif dengan metode survey. Penelitian deskriptif adalah penelitian yang dimaksudkan untuk untuk menyelidiki, keadaan, kondisi, atau hal-hal lain yang disebutkan, yang hasilnya dipaparkan dalam laporan penelitian (Suharsimi, 2013). Teknik pengambilan data yang digunakan dalam penelitian ini adalah teknik purposive sampling dengan pertimbangan tertentu sesuai dengan tujuan yang dikehendaki (Sugiyono, 2016). Subjek penelitian adalah seluruh mahasiswa program studi PG PAUD FKIP Universitas Muhammadiyah Prof. DR. HAMKA yang mengambil mata kuliah Pengembangan Kurikulum pada
Tahun Akademik 2019/2020 berjumlah 22 orang. Pengumpulan data menggunakan angket dan dokumentasi, sedangkan teknik analisa data menggunakan analisis deskriptif kuantitatif. Lokasi penelitian di kampus FKIP Universitas Muhammadiyah Prof. DR. HAMKA, Jakarta.

Data akan dianalisa setelah dihitung menggunakan teknik persentase dengan rumus :

$$
\begin{aligned}
& \mathbf{P}=\frac{\boldsymbol{f}}{\boldsymbol{N}} \boldsymbol{x} \mathbf{1 0 0} \% \\
& \mathrm{P}=\text { persentase } \\
& f=\text { jumlah jawaban yang } \\
& \text { diperoleh } \\
& \mathrm{N}=\text { jumlah responden } \\
& \text { keseluruhan }
\end{aligned}
$$

\section{HASIL DAN PEMBAHASAN}

A. Kurikulum Tingkat Satuan Pendidikan (KTSP)

Kurikulum Tingkat Satuan Pendidikan untuk PAUD adalah kurikulum operasional yang dikembangkan dan dilaksanakan sesuai dengan karakteristik satuan PAUD, seperti keadaan lingkungan, pendidik, peserta didik, sarana prasarana, biaya, dan nilai-nilai yang mendasari, serta program yang akan dilakukan oleh satuan PAUD (Nugraha, Nurmiati, Wahyuningsih, \& Wujiati, 2018). KTSP setiap lembaga mempunyai kekhasan karena merupakan acuan lembaga dalam menyelenggarakan program, melaksanakan berbagai layanan di lembaga, dan melaksanakan proses pembelajaran dan evaluasi hasil 
belajar sesuai dengan karakteristik satuan PAUD.

Melalui model project based learning dosen memberikan penugasan kepada mahasiswa untuk menyusun rancangan Kurikulum Tingkat Satuan Pendidikan PAUD dengan 4 karakteristik satuan PAUD yang berbeda, yaitu PAUD berbasis agraris, PAUD berbasis maritime, PAUD di daerah rawan bencana, dan PAUD inklusi. Dengan memberikan perbedaan karakteristik satuan PAUD, mahasiswa diharapkan mampu marancang inovasi kurikulum PAUD dan bisa menjadi rekomendasi bagi lembaga-lembaga PAUD yang mempunyai karakteristik sejenis.

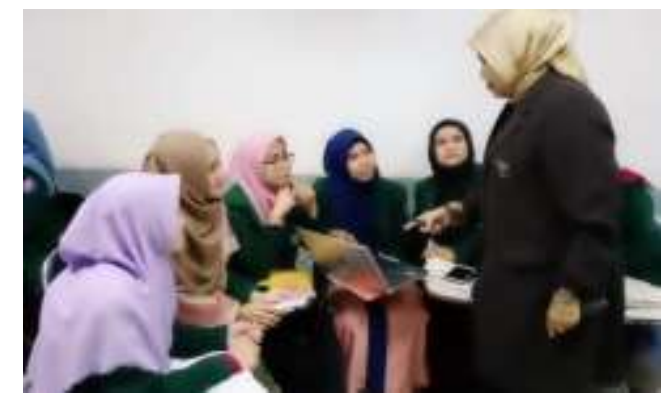

Gambar 1. Dosen Memberikan

Penugasan Proyek Penyusunan KTSP

Mahasiswa melaksanakan proyek dalam waktu 1 bulan bersama dengan kelompoknya. Proyek dimulai dengan analisis konteks dengan mengumpulkan berbagai informasi tentang kondisi geografis satuan PAUD, keragaman potensi sumber daya, ketersediaan sarana prasarana, keragaman latar belakang dan kondisi sosial budaya, dan lain sebagainya. Mahasiswa melakukan studi literatur dan diskusi kelompok analisis konteks disertasi landasan hukum perundang-undangan pengembangan kurikulum PAUD, antara lain Peraturan Menteri Pendidikan dan Kebudayaan Tahun 2014 Nomer 137 tentang Standar Nasional PAUD dan Nomer 146 tentang Kurikulum Tahun 2013 Pendidikan Anak Usia Dini, Melalui project based learning, mahasiswa mengerjakan proyek secara sistematis melalui proses inquiry yang terstruktur dan sistematis.

Proses pengerjaan proyek selanjutnya adalah penyusunan dokumen KTSP PAUD, yang terbagi menjadi dokumen 1 dan dokumen 2. Dalam menyusun KTSP, mahasiswa memperhatikan prinsip-prinsip penyusunan KTSP yaitu berpusat pada anak, kontekstual, kompetensi dan dimensi perkembangan, pembentukan kepribadian, sesuai tahap perkembangan, sesuai dengan cara belajar, holistik integratif, melalui bermain, membangun pengalaman belajar, dan sesuai dengan konteks sosial budaya. Dalam dokumen 1 KTSP, mahasiswa harus bisa merumuskan visi misi satuan PAUD sesuai dengan karakteristik satuan PAUD, tujuan satuan PAUD, program pengembangan, indikator pencapaian perkembangan anak, muatan pembelajaran, pengaturan 
beban belajar, dan kalender pendidikan. Proyek dilanjutkan dengan penyusunan dokumen 2 KTSP. Dalam dokumen 2 KTSP, mahasiswa menyusun Program Semester, Rencana Pembelajaran Mingguan, Rencana Pembelajaran Harian, dan Rencana Penilaian Perkembangan.

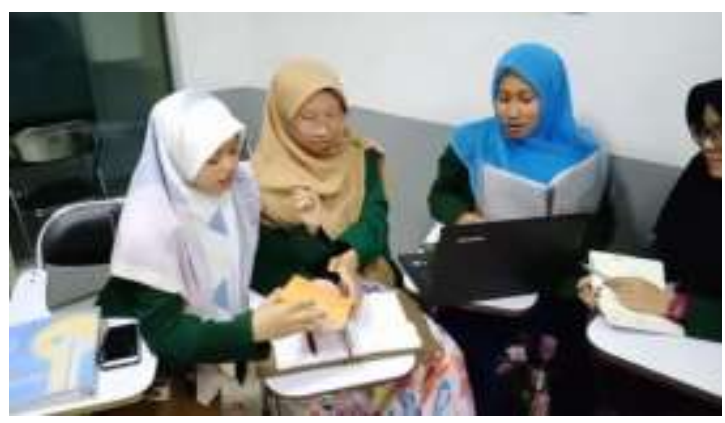

Gambar 2. Diskusi Kelompok Penyusunan KTSP PAUD

Melalui model project based learning mahasiswa menujukkan kinerja kreatif secara kolaboratif dan inovatif, dengan menggunakan sumber belajar multidimensi dengan menitikberatkan pada metode inquiry dan discovery. Dengan project based learning setiap kelompok mahasiswa menghasilkan rancangan Kurikulum Tingkat Satuan Pendidikan (KTSP) dengan karakteristik PAUD yang berbedabeda, yaitu KTSP untuk PAUD berbasis agraris, PAUD berbasis maritim, PAUD di daerah rawan bencana, dan PAUD inklusi.

\section{B. Persepsi Mahasiswa}

Dalam penelitian ini, persepsi mahasiswa terhadap model project based learning $(P B L)$ dalam penyusunan KTSP terbagi menjadi empat yaitu : 1) Persepsi mahasiswa apakah melalui model project based learning dalam menyusun KTSP meningkatkan penguasaan mata kuliah pengembangan kurikulum; 2) Persepsi mahasiswa apakah melalui model project based learning meningkatkan kedalaman analisis pengembangan kurikulum; 3) Persepsi mahasiswa apakah setiap guru penting untuk menguasai keterampilan menyusun KTSP; 4) Persepsi mahasiswa apakah akan mengaplikasikan keterampilan menyusun KTSP saat menjadi guru PAUD.

Angket diberikan kepada seluruh mahasiswa semester 5 program studi PG PAUD FKIP UHAMKA dengan skala Guttman dengan pilihan angka 1 untuk setuju, dan angka 2 untuk tidak setuju. Hasil pengolahan data menunjukkan:

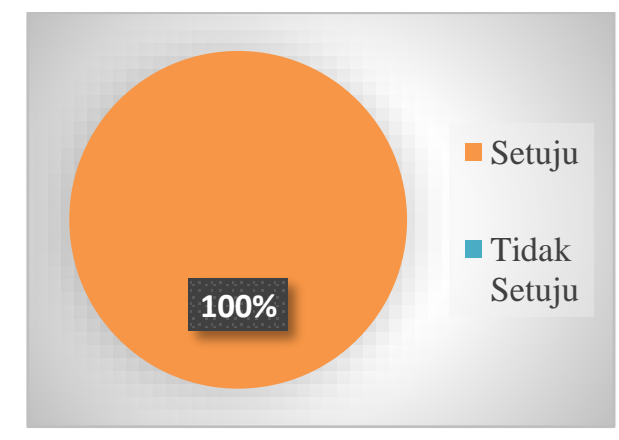

Diagram 1. Model PBL Meningkatkan Penguasaan Materi Pengembangan Kurikulum

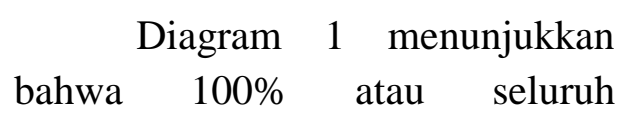


mahasiswa setuju bahwa model project based learning dalam penyusunan KTSP meningkatkan penguasaan materi Pengembangan Kurikulum. Melalui proyek, seluruh mahasiswa terlibat aktif dalam mencari referensi sumber belajar dan diskusi bersama kelompok, sehingga meningkatkan penguasaan materi mata kuliah Pengembangan Kurikulum.

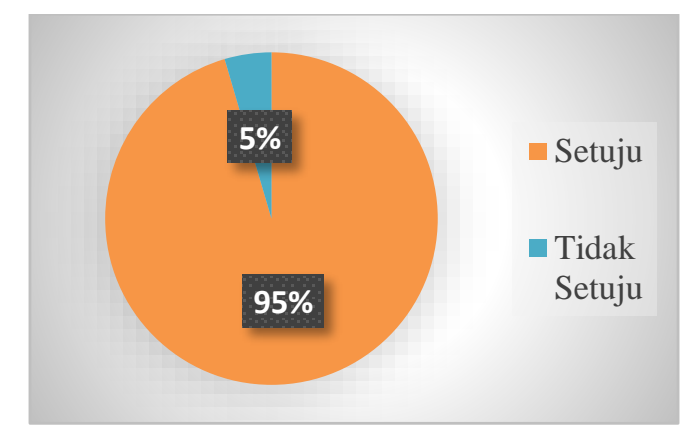

Diagram 2. Model PBL Akan

Meningkatkan Kedalaman Analisis

Pengembangan Kurikulum

Diagram 2 menunjukkan bahwa sebanyak 95\% mahasiswa mata kuliah Pengembangan Kurikulum setuju bahwa model project based learning meningkatkan kedalaman analisis pengembangan kurikulum. Melalui kerja proyek, mahasiswa memahami bahwa KTSP PAUD bukan seragam dan mampu menganalisis secara mendalam perbedaan KTSP PAUD berdasarkan karakteristik yang dimiliki tiap satuan PAUD. Perbedaan karakteristik satuan PAUD menjadi kekhasan kurikulum tiap satuan.

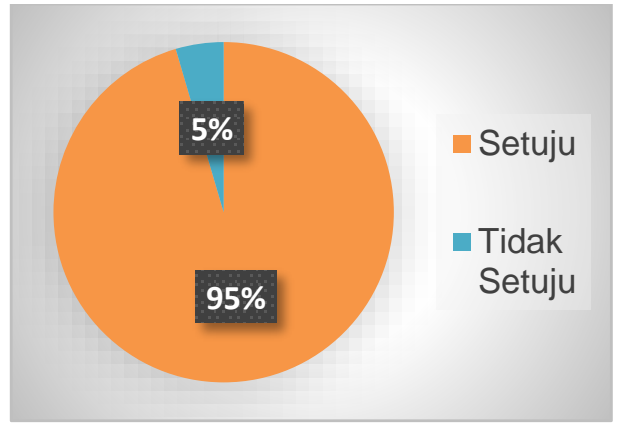

Diagram 3.

Setiap Guru PAUD Harus

Menguasai Keterampilan

Menyusun KTSP

Diagram 3 menunjukkan bahwa 95\% mahasiswa setuju bahwa guru PAUD harus mempunyai keterampilan menyusun KTSP. Guru PAUD harus menguasai pembuatan perencanaan, pelaksanaan, dan penilaian karena guru PAUD adalah ujung tombak pendidikan.

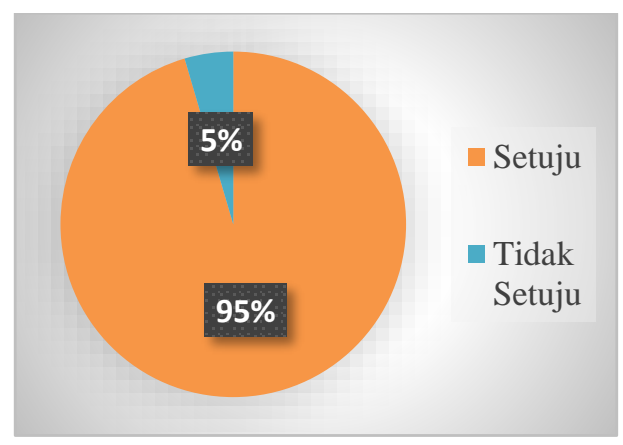

Diagram 4. Mahasiswa Akan

Mengaplikasikan Keterampilan Menyusun KTSP Setelah Menjadi Guru PAUD

Diagram 4 menunjukkan bawa 95\% mahasiswa setuju akan mengaplikasikan keterampilan menyusun KTSP saat menjadi guru PAUD. Mahasiswa menemukan 
data bahwa di lapangan saat ini banyak lembaga PAUD tidak mempunyai tim pengembang kurikulum, sehingga kurikulum satuan PAUD tidak mengalami perubahan dan bahkan ditemukan beberapa satuan PAUD yang membeli dokumen KTSP dari pihak lain atau mengunduh dari internet. Hal tersebut sangat tidak tepat karena kurikulum belum tentu sesuai dengan karakteristik tiap satuan PAUD.

\section{SIMPULAN}

Hasil penelitian menunjukkan bahwa persepsi mahasiswa terhadap model project based learning dalam penyusunan KTSP adalah : 1) $100 \%$ mahasiswa mengatakan setelah menyusun KTSP melalui project based learning meningkatkan penguasaan mata kuliah pengembangan kurikulum; 2) $95 \%$ mahasiswa menyampaikan bahwa melalui project based learning meningkatkan kedalaman analisis pengembangan kurikulum; 3) $95 \%$ mahasiswa menyampaikan bahwa setiap guru harus menguasai keterampilan menyusun KTSP; 4) 95\% mahasiswa menyampaikan bahwa akan mengaplikasikan keterampilan menyusun KTSP saat menjadi guru PAUD.

\section{DAFTAR PUSTAKA}

Depdiknas. (2003). Undang-Undang RI No 20 Tahun 2003. In UndangUndang Republik Indonesia
Nomor 20 Tahun 2003 Tentang Sistem Pendidikan Nasional Dengan Rahmat Tuhan Yang Maha Esa Presiden Republik Indonesia.

Direktorat Akademik, D. (2008). Panduan Pengembangan

Kurikulum Berbasis

Kompetensi Pendidikan Tinggi.

Direktorat Akademik

Direktorat Jenderal Pendidikan Tinggi, 49. Retrieved from http://www.unud.ac.id/ind/wpcontent/uploads/bukupanduan-kurikulumkbk.pdf\%5Cnhttp://s3.amazon aws.com/academia.edu.docum ents/44192457/BUKU-

Panduan-

KBK.pdf?AWSAccessKeyId= AKIAIWOWYYGZ2Y53UL3 A\&Expires $=1486971733 \&$ Sig nature $=$ XnmjSoeYP2XJCPQm cDpd4C6yhy4\%3D\&res

Fardan Ngoyo, M. (2015). Mengawal Sustainable Development Goals(SDGs); Meluruskan Orientasi Pembangunan yang Berkeadilan. Journal of Sleep Research. https://doi.org/10.1111/jsr.122 13

ILO. (2018). Tujuan Pembangunan Berkelanjutan, Referensi Manual Serikat Pekerja Pada Agenda untuk Pembangunan Berkelanjutan. Jakarta: Organisasi Perburuhan Internasional.

Insyasiska, D., Zubaidah, S., Susilo, H., Biologi, P., \& Malang, U. N. (2015). Pengaruh Project Based Learning Terhadap Motivasi Belajar, Kreativitas, Kemampuan Berpikir Kritis , dan Kemampuan Kognitif 
Siswa Pada Pembelajaran

Biologi. Jurnal Pendidikan Biologi, 7.

Nugraha, A., Nurmiati, Wahyuningsih, S., \& Wujiati. (2018). Penyusunan Kurikulum Tingkat Satuan Pendidikan (E. Yulaelawati \& K. Restuningsih, eds.). Direktorat Pembinaan Pendidikan Anak Usia Dini, Direktorat Jenderal PAUD Dikmas, Kemdikbud.

Nurdin, S. (2017). Pengembangan Kurikuum dan Rencana Pembelajaran Semester ( RPS ) Berbasis KKNI di Perguruan Tinggi. Jurnal Al-Fikrah, 1.

Nurjaman, I., Rachmi, T., \& Arjulayana. (2019). Persepsi Orang Tua Terhadap Pemerolehan Bahasa Inggris Anak Usia Dini. Early Childhood: Jurnal Pendidkan, 3(2), 82-90.

Nurwardani, P., Roy, R., Mulyono, E., Nugroho, S. W., Edrotomo, Arifin, S., ... Priyautama, F. (2016). Panduan Penyusunan Kurikulum Pendidikan Tinggi (2nd ed.). Jakarta: Direktorat Jenderal Pembelajaran dan Kemahasiswaan, Kementerian Riset Teknologi dan Pendidikan Tinggi.

Sugiyono, P. D. (2016). Metode Penelitian Kuantitatif, Kualitatif, dan R\&D. In Alfabeta, $c v$.

Suharsimi, A. (2013). Prosedur Penelitian: Suatu Pendekatan Praktik (Edisi Revisi). In Jakarta: Rineka Cipta. https://doi.org/10.1017/CBO97 81107415324.004

Sutirman. (2013). Media \& ModelModel pembelajaran Inovatif.
Retrieved from http://opac.library.um.ac.id/oai $\mathrm{pmh} / . . /$ index.php?s_data $=b p \_b$ uku\&s_field $=0 \& \bmod =$ b\&cat $=$ $3 \& \mathrm{id}=44693$

Trisnowati, E., Ismawati, R., \& Tidar, U. (2018). Profil Persepsi Mahasiswa Terhadap Model Pembelajaran Project Based Learning. 58-63. 